Pre-Print version

\title{
Gender Differences in Discharge Destination Following Traumatic Brain Injury
}

\section{Introduction}

Traumatic brain injury (TBI) is a leading cause of death and disability worldwide (Colantonio et al, 2009). Recent literature in cardiovascular research has reported a sex bias in the management of patients, with men receiving more aggressive treatment than women. In a study of stroke patients, men over the age of 85 were more likely to be prescribed aspirin and ticlopidine as well as more likely to be discharged home than to a chronic care facility than their female counterparts (Holroyd-Leduc et al, 2000). There currently exists a growing body of literature reporting gender differences in medical and psychosocial outcomes following TBI. A study by Farace and Alves (2000) conducted a meta-analysis of gender differences in outcomes in those with TBI and found that women fared worse in $85 \%$ of the measured variables. Investigators have also found gender differences in cognitive and emotional adjustment to TBI where women experience higher levels of depression, while men report greater general psychological distress (Schopp et al, 2001). This is significant as an increased rate of depression can have widespread negative effects on the quality of life after TBI (Hibbard et al, 2004).

Women are less likely to be married following brain injury than men (Colantonio et al, 2003). It is therefore important to examine whether gender differences exist in the discharge destination from acute care settings among TBI survivors. It is possible that the protracted and incomplete recoveries women experience post-TBI may be partly explained by the social isolation and lack of support networks characteristic of 
Pre-Print version

institutional care. No research has yet been done examining sex based differences in discharge destination following TBI. The present study explores the differences in discharge destination following TBI between male and female TBI survivors, while controlling for age, mechanism of injury, injury severity scores (ISS), and length of stay (LOS) in those individuals 65 years and older.

\section{$\underline{\text { Data Source }}$}

Data for this study was obtained from the minimal data set of the Ontario Trauma Registry. This is a validated database that describes and quantifies TBI occurrence in the province of Ontario and the minimal data set includes the demographic, diagnostic and procedural information on all patients admitted to acute care hospitals in Ontario during the fiscal years of 1993-1994 and 2000-2001. The data set used for this particular analysis was adjusted from a previous study on discharge destination (Kim et al, 2006).

\section{Methods}

The data has been organized so that the variable of age is separated into groups of five year intervals. For this analysis only individuals over the age of 65 were included. Also, injury groups were categorized into mild vs. moderate/severe based upon LOS in hospital. Only moderate/severe TBI cases were included in this study as most mild TBI patients are discharged home following a short $24-48$ hours hospital stay. Therefore, all persons admitted into acute hospital care in Ontario aged 65 or over, presenting with a moderate/severe (based upon LOS) TBI as defined by the ICD-9-CM, the International Classification of Diseases, $9^{\text {th }}$ version (N800-804; N850-854) codes were included in this study $(n=3,480)$. Moderate/severe TBI cases were defined as LOS greater than two days in the hospital. 
Pre-Print version

\section{Variables Measured}

Demographic variables include sex and age which was categorized into five year intervals.

Mechanism of injury was divided into two groups: motor vehicle accidents versus falls and other. Frequently, the cost of care sustained as a result of motor vehicle accident injuries are covered by private insurance companies (Kim et al, 2005). Therefore, mechanism of injury can be used as a proxy for private medical insurance that is available over and above public health insurance available to all residents of the province. This is a factor that must be controlled for when considering discharge destination as those with comprehensive coverage may be entitled to more healthcare services. We recognize that this is a proxy measure however and that an unspecified proportion of participants who sustained TBIs by other mechanisms may also have private insurance.

Injury Severity was measured by the Injury Severity Score (ISS) and LOS. ISS is a summary score for injury severity based upon six body regions; the higher the score, the more serious are the patient's injuries (Cooke et al, 1995). LOS refers to the duration (in days) the patient spends in the hospital in acute care following the initial injury. LOS is a well known predictor of rehabilitation outcomes. Typically, the shorter the LOS, the better the patient's functional outcome (Aras, Kaya, Cakci, Gokkaya, 2004).

Discharge destination in the original data set was broken down into four groups: long term care facility, other facility, home with support services and home without support, see figure 1. For the purposes of this analysis, the discharge destination was contracted into two groups: "home" and "care facility." This was done in order to 
Pre-Print version

determine whether women are less likely to be discharged home than men.

\section{Analysis}

The study analysis sought to explore whether or not there is a gender difference in discharge destination following hospitalization for TBI. Age, mechanism of injury ISS and LOS were all determined to be potentially confounding and were therefore included as covariates to the independent variable in the logistic analysis. Analysis of this data was performed using SPSS 12.00.

\section{$\underline{\text { Results }}$}

The average age of the over 65 age groups was 76 . In general, most people were discharged home, however, a greater percentage of the individuals sent to care facilities were women (24\% vs. $17 \%)$.

\section{Insert figure 1 about here}

Age, as expected, was found to be a significant predictor of discharge destination, with older populations being sent home with greater frequency $(\mathrm{p}<0.05)$. Similarly, LOS and mechanism of injury were found to be significant predictors of discharge destination; the longer the LOS, the greater the likelihood of being discharged to a care facility $(\mathrm{p}<0.05)$. Table 1 indicates that ISS was not found to be a significant predictor of discharge destination $(\mathrm{p}>0.05)$. Further, a chi-square test revealed a significant difference between the two genders' discharge destination following TBI hospitalization (Pearson chi-square, $\mathrm{p}<0.05$ ). Binary logistic regression was employed 
Pre-Print version

and a significant difference in discharge destination between the genders was found, as included in Table 2, with women being 1.3 times more likely to be discharged to a care facility rather than a home setting than their male counterparts $(\mathrm{p}<0.05)$. Further, Table 2 outlines that individuals who sustained a TBI due to a fall or some other mechanism of injury were twice as likely to be sent to a care facility versus home compared to those who sustained a TBI during a motor vehicle accident.

\section{Insert table 1 about here Insert table 2 about here}

\section{$\underline{\text { Discussion }}$}

The results support the hypothesis that women are sent to care facilities more frequently than men. However, the reasons accounting for this difference have not yet been elucidated. Since women are generally the primary caregivers in the home environment, it is possible that once they are no longer able to fill that role no family members are available, or willing, to transfer into the care giving role. Also, women tend to outlive their partners and therefore it is possible that elderly women TBI survivors are forced into a care facility as they are no longer competent to function in their home alone.

As was expected, the longer the LOS, the more likely individuals are sent into a care facility. A longer LOS is associated with worsened functional outcomes and it is therefore not surprising that these TBI survivors would require greater care than is typically available within a home setting. In contrast, the finding that increasing age is associated with being discharged home was unexpected. Further analysis surrounding circumstances of injuries should be examined before this result can be discussed further. 
Pre-Print version

ISS was not found to be a significant independent predictor. This suggests that a number of contributing factors may be involved in functional recovery aside from severity of injury (comorbidity factors, attitude, physical fitness prior to injury, etc.) and these may prove to be more predictive of discharge destination than ISS alone.

Mechanism of injury was found to be a significant predictor of discharge destination, as expected. This difference in discharge destination can likely be attributed to the availability of private insurance to cover the costs of home care for which the province has no legal obligation to provide according to the Canada Health Act. This is particularly important given the Ontario healthcare system's growing tendency to discharge patients earlier from acute care, potentially creating a two tiered system wherein those who are able to pay for private insurance will be able to remain in the home setting following major trauma and those who do not will be sent away to a care facility. More research needs to be performed in order to better understand the impact such a system may have on patient outcomes.

One limitation of this analysis is the lack of information concerning comorbid factors, particularly considering the population's age, that might be associated with gender. Similarly, other sociodemographic variables, such as socioeconomic status, and the occurrence of previous head injuries would be important factors to control for in future studies.

Thus, gender is a significant predictor of discharge destination following TBI. However, mechanism of injury, LOS, and age are also predictors and it is more than likely that other factors may contribute also. Further analysis must be done to determine why gender is a predictor; at this stage only speculation is possible. It is likely that a 
Pre-Print version

decline in social support networks in the home follows from the loss of the primary caregiver, often the matriarch. Consequently, injured women are left with no one to care for them and are therefore sent away from the home to alternate care facilities. Further research must be done to explore how this gender difference in discharge destination is implicated among the gender differences in medical and psychological outcomes postTBI.

\section{References:}

Aras M D, Kaya A, Cakci A \& Gokkaya K. Functional outcome following traumatic brain injury: the Turkish experience. International Journal of Rehabilitation Research 2004; 27:257-60.

Colantonio A, Ratcliff G, Chase S \& Al-Sukni E. Health issues of women many years after traumatic brain injury. Ontario Neurotrauma Foundation Inaugural Provincial Conference on SCI and TBI Research: Building Bridges to Discovery and Independence; 2003; Toronto.

Colantonio A, Ratcliff G, Chase S, Kelsey S, Escobar, M \& Vernich L. Long term outcomes after moderate to severe traumatic brain injury. Disability and Rehabilitation 2004; 26(5): 253-261.

Farace E \& Alves WM. Do women fare worse: A meta-analysis of gender differences in traumatic brain injury outcome. Journal of Neurosurgery 2000; 93(4): 539-45.

Hibbard M, Ashman T, Spielman L, Chun D, Charatz H \& Melvin S. Relationship between depression and psychosocial functioning after traumatic brain injury. Archives of Physical Medicine and Rehabilitation 2004; 85(4): S43-53.

Holroyd-Leduc J, Kapral M, Austin P \& Tu J. Sex differences and similarities in the management and outcome of stroke patients. Stroke 2000; 31: 1833-7.

Kim H, Colantonio A, Deber R \& Vernich L. Discharge destination from acute care after traumatic brain injury. Canadian Journal of Neurological Sciences 2006; 33: 48-52.

Schopp L, Shigaki C, Johnstone B \& Kirkpatrick H. Gender differences in cognitive and emotional adjustment to traumatic brain injury. Journal of Clinical Psychology in Medical Settings 2001; 8(3): 181-7. 
Pre-Print version 
Pre-Print version

Table 1

\begin{tabular}{|c|c|c|c|}
\hline Variable & $\begin{array}{c}\text { Males } \\
(\mathrm{n}=1581)\end{array}$ & $\begin{array}{c}\text { Females } \\
(\mathrm{n}=1899)\end{array}$ & p-value \\
\hline Mean Age (years) & 74 & 78 & $<0.001$ \\
\hline Mean LOS (days) & $17.0(25.2)$ & $17.0(26.5)$ & 0.4 \\
\hline Mean ISS (SD) & $9.4(6.7)$ & $9.6(7.0)$ & 0.27 \\
\hline $\begin{array}{c}\text { Mean Number of } \\
\text { comorbidities (SD) }\end{array}$ & $3.2(2.7)$ & $3.3(2.8)$ & 0.39 \\
\hline $\begin{array}{c}\text { Mechanism of Injury } \\
\text { MVC }\end{array}$ & $\begin{array}{c}242(15 \%) \\
\text { Falls/Other }\end{array}$ & $\begin{array}{c}222(12 \%) \\
1677(88 \%)\end{array}$ & $<0.05$ \\
\hline $\begin{array}{c}\text { Discharge destination } \\
\text { Home }\end{array}$ & $1311(83 \%)$ & $1435(76 \%)$ & $<0.001$ \\
Away & $270(17 \%)$ & $464(24 \%)$ & \\
\hline
\end{tabular}


Pre-Print version

Table 2

\begin{tabular}{|c|c|c|c|}
\hline Variable & $\begin{array}{c}\text { Odds } \\
\text { Ratio }\end{array}$ & $\begin{array}{c}95 \% \\
\text { Confidence } \\
\text { Interval }\end{array}$ & p-value \\
\hline Female & 1.30 & $1.056-1.591$ & 0.0131 \\
\hline $\begin{array}{c}\text { Age group } \\
\text { ISS* }\end{array}$ & 1.50 & $1.407-1.605$ & $<0.001$ \\
\hline $\begin{array}{c}\text { LOS in days } \\
\text { (MVC vs } \\
\text { falls/other) }\end{array}$ & 1.03 & $1.020-1.030$ & $<0.001$ \\
\hline $\begin{array}{c}\text { Comorbidities } \\
\text { injury }\end{array}$ & 1.08 & $1.046-1.122$ & $<0.001$ \\
\hline $\begin{array}{c}\text { Mechanism of } \\
\text { (M) }\end{array}$ & 0.54 & $0.370-0.799$ & 0.0019 \\
\hline
\end{tabular}

*Using stepwise regression, ISS did not stay at a level of significance.

\section{Figure Captions}

Figure 1: Discharge destination by gender

Table 1: Key variables by gender

* Chi-square tests were used for mechanism of injury and discharge destination, Mann-Whitney test used for age group, LOS, ISS.

Table 2: Predictors of institutionalization post discharge after TBI: multivariate logistic regression analysis

*Variables entered the model: type of injury (falls and other), sex (female), age, and LOS. Using stepwise regression, ISS did not stay at a level of significance. 